\title{
Observing the Observers: Researching Surveillance and Counter-Surveillance on 'Skid Row'.
}

\author{
Thomas Kemple1 and Laura Huey ${ }^{2}$
}

\begin{abstract}
Using empirical research drawn from field studies on the policing of 'skid row' communities, this paper illustrates some of the theoretical, methodological and ethical problems that confront the researcher who studies surveillance and counter-surveillance within these contested settings. We begin by noting how, with the increasing use of the 'broken windows' policing model to regulate deviant individuals and to secure derelict urban spaces, researchers may be implicated in the use of surveillance and counter-surveillance by community stakeholders. Drawing examples from direct and covert field observations, field notes, and photographs, we demonstrate that there is a significant potential for the researcher to become identified as an agent of surveillance, and as a potential target of counter-surveillance, within such settings. We conclude by considering some of the theoretical, methodological and ethical implications of the researcher's complicity in these dynamics for both the conduct of surveillance studies in general, and for urban fieldwork in particular.
\end{abstract}

Quis custodiet ipsos custodes?

(Who shall watch the watchers? - Juvenal)

\section{Introduction}

What has historically been referred to as 'skid row' is both a highly contested physical space and an intensely conflicted moral order. Within these urban zones, drug dealers fight turf wars, prostitutes vie for corners, while 'respectable' families and local businesses launch community watches and neighborhood reclamation projects directed at removing problematic 'others.' At the same time, public police and private security agents attempt various measures to 'take back' the streets from targeted residents and community groups who actively resist such efforts. The term 'skid row' has itself long been at the center of conflicts over the naming of this space and the people who live there. These battles are fought between neighborhood organizations, municipal authorities and a

1 Department of Sociology, University of British Columbia, Vancouver, B.C., Canada. mailto:kemple@interchange.ubc.ca
2 Department o mailto:laurah@,telus.net 
variety of other stakeholders (Huey and Kemple, 2005; Hasson and Ley, 1994: 189-201). Such spatial, symbolic and political struggles render this area an important site in which to study the use of low-level surveillance and counter-surveillance measures: to the extent that disparate groups compete to stamp their social, political and/or economic agendas on the physical location, they often use surveillance and counter-surveillance techniques as components of their arsenals of domination and resistance. At the same time, the volatility of these dynamics presents the urban field researcher with a number of methodological and ethical challenges.

This essay discusses an important consideration arising from the surveillance researcher's function as an analyst of relations of power and knowledge within the contested physical, cultural and moral space of 'skid row.' In particular it concentrates on how as a consequence of conducting systematic disciplined observation of subjects in the field in order to uncover the surveillance and counter-surveillance strategies used by others, the researcher herself may become a subject of surveillance. Further, the intensity and proximity of the researcher's involvement in this field of observation may also lead her to be identified as an agent of surveillance, and thus to become a potential target of countersurveillance. The methodological, theoretical and ethical significance of this phenomenon for the research process, understood as a form of social interaction and struggle in its own right, has important implications for the conduct of surveillance studies in general, and of urban field research in particular.

This paper is structure to follow two main axes of critical analysis and self-reflection. First, after offering a brief introduction to the setting and subjects of the two empirical studies from which we draw our observations, we develop a reflexive discussion of the methods employed in this research in terms of how sociological observation may be implicated in the surveillance strategy of so-called 'broken windows' policing. Second, we situate recent developments in the policing of 'skid row' by illustrating the problem of how the researcher may herself be positioned as the subject of surveillance or viewed as an agent of counter-surveillance. In each instance we offer a critical analysis of first-hand accounts from the field of how the sociological observer both studies and is immersed in techniques of surveillance and counter-surveillance. A concluding section further problematizes the methodological-epistemological and ethical-political implications of this phenomenon for field study and considers the extent to which the issues we have raised are unique to skid row research or whether they might be generalizable to other aspects of surveillance studies.

\section{Sociological Observation and 'Broken Windows' Surveillance}

Conduct is continually monitored and reshaped by logics immanent within all networks of practice. Surveillance is 'designed in' to the flows of everyday existence. The calculated modulation of conduct according to principles of optimization of benign impulses and minimization of malign impulses is dispersed across the time and space of ordinary life

(Rose, 1999: 234).

Among the several shades of meaning of the verb 'to observe' listed in Webster's, perhaps 
the two most common usages are "to conform one's action or practice" (i.e. to laws, customs, ceremonies, or rules) and "to see or sense, esp. through directed careful analytic attention" (i.e. to noted facts, evidence, knowable realities). It seems then that observation, whether casual and ordinary or disciplined and professional, is inescapably ingrained in relations of knowledge (especially when acquired through visual perception) and power (particularly involving compliance with established conventions of authority). This essay draws from two larger ethnographic studies of public and private policing in so-called 'skid row' districts that exhibit each of these dimensions of observational practice. $^{3}$ What we call 'the private security study,' was conducted in 2000 and examined the use of 'broken windows-style' policing by private security agents to regulate the presence of suspicious or disorderly individuals in a gentrified area of Vancouver's historic 'skid row' district commonly referred to as Gastown (Huey, Ericson and Haggerty, 2005). The second project, conducted in 2003 and referred to as 'the public policing study,' explored the politics of public policing in skid row districts in the San Francisco Tenderloin district, Vancouver's Downtown Eastside and Edinburgh's Cowgate and Grassmarket neighborhood (Huey, 2005). While the primary focus of both studies was on the policing of skid row districts, a principal research goal in each was more generally to examine the extent to which routine surveillance of target populations was being undertaken by public and/or private policing agencies within these communities. Although for the purposes of illustration in the present essay we draw mostly from the relevant geographical, cultural and political particularities of the Vancouver site, it is important to note that the other two sites exhibit similar characteristics with respect to the composition of the population and the use of surveillance and counter-surveillance as a means to control territory.

As surveillance is a broad concept used to describe a wide range of phenomena - from the use of infrared technology in military helicopters to the ways in which individuals routinely spy on their neighbors - we must also clarify our use of this term. Following Gary Marx (2003: 370), we define surveillance as those technologies of visibility and techniques of exposure that "seek to eliminate privacy in order to determine normative compliance or to influence the individual" for particular aims or interests. Marx (2004: 276) further provides a useful contrast between 'traditional surveillance,' defined as "close observation, especially of a suspected person,: and its new forms, which he characterizes as "scrutiny through the use of technical means to extract or create personal or group data, whether from individuals or contexts." We are reporting on studies which examined the use of relatively low-tech surveillance on skid row by police, private security, and community watch groups, on the one hand, and on the other hand, surveillance used by traditional targets of normative surveillance, including buyers and sellers in the drug, prostitution and/or stolen goods markets, and other individuals similarly defined as 'deviant others.' Here our concern is less with the extension or intensification of sophisticated surveillance techniques as such (for example, in the

\footnotetext{
${ }^{3}$ As the present essay is about performing research in a particular type of contested territory, our use of the morally freighted and stigmatized term 'skid row' is a deliberate choice. In using it we draw explicit attention to the historic and contemporary association of particular geographical and social locations with predominant moral attitudes that lead to the social neglect and/or harsh treatment of citizens. Also, since fieldwork for both studies was conducted by Laura Huey, in what follows we use the feminine pronoun when referring to 'the researcher' in the field, even when this term is used generically.
} 
interests of business or government) than with the asymmetrical, anonymous, and nonreciprocal surveillance of vulnerable or suspicious social groups in public spaces. What these practices share is the use of surveillance techniques and strategies for: 1) classifying and interpellating identities within a moralized physical space, for example to distinguish 'good' residents (and/or others who use these spaces) and zones from those designated as 'bad,' and 2) fostering compliance with a particular set of normative values in that space. Rather than follow the lead of other researchers who have focused on these contested fields of surveillance and counter-surveillance themselves (Marx, 2003: Lyon, 2002; Staples, 2000), our primary aim is to examine the extent to which the research enterprise itself - through direct observation, note-taking, photography, and the subsequent accumulation and analysis of visual and recorded data - is inextricably embedded within similar and overlapping relations of power and knowledge.

A total of 161 individuals identified as stakeholders were interviewed for both studies. They were selected because they were identified as different forms of stakeholders with an interest in these spaces. This included 'street level' users of these spaces (including 46 area residents, 14 business owners and 8 tourists), front-line professionals (including 46 police officers and private security agents and 36 members of community groups), and civic officials ( 8 individuals). At the risk of oversimplification, we characterize these various stakeholders in terms of their location within a broader set of practices that have come to be referred to as the 'broken windows' strategy of maintaining law and order. 'Broken windows' policing was initially promoted over twenty years ago on the assumption that minor infractions, or more precisely, the visible signifiers of decay and neglect such as litter, graffiti, and broken windows tend to produce criminogenic effects including theft, prostitution, and drug-trafficking. When combined, these behaviors increase and legitimate the fears of 'respectable' citizens (Wilson and Kelling, 1982). The view that minor incivilities lead to major crimes is itself based on the assumption that visual environmental cues mark a territory as 'undefended' and therefore lacking in social controls. This approach has since been expanded from an informal policing policy to a more generalized civic strategy of surveillance and counter-surveillance (Johnston and Shearing, 2003: 102; Huey, Ericson and Haggerty, 2005). Public police, private security officers, and civic officials have increasingly favored the 'recruitment' of area residents, business owners, and community groups to help produce the outward appearance of order and to regulate images of disorder on skid row (Ellickson, 1996; Kelling and Coles, 1996). Beyond the institutionally sanctioned efforts of public police and private security officers, various community members have been solicited to participate in a wide range of practices of impression-management and social control. These can entail acts such as removing delinquents from public places, informing on criminals, or simply assisting the disadvantaged and keeping a watch on 'deviants' in the area. 'Broken windows' then is not just a reactive zero-tolerance policing strategy that makes use of coercive force; it may also (or alternatively) involve pre-emptive ceremonial displays of symbolic power.

Figure 1 displays these modes of adaptation and resistance imaginatively in the form of a 'window' onto the contested social field of 'skid row surveillance.' Here 'order' refers to the culturally prescribed goal of this strategy as it is normally defined in terms of middle class standards of consumption and socially dominant values of decorum, civility and respectability. 'Law' is understood as the institutionally legitimized means for achieving this goal as it is formally defined by legislative statutes that are enforced by public 
authorities, or as it is informally upheld by various private and other public agents who may or may not be authorized to operate in an official capacity. When arranged to suggest the coordinates of a grid (the heuristic device suggested by Figure 1), 'law' and 'order' represent a virtual frame for how the social space of 'skid row' is occupied by differently located social actors operating across a range of conflicting or complementary relationships. ${ }^{4}$

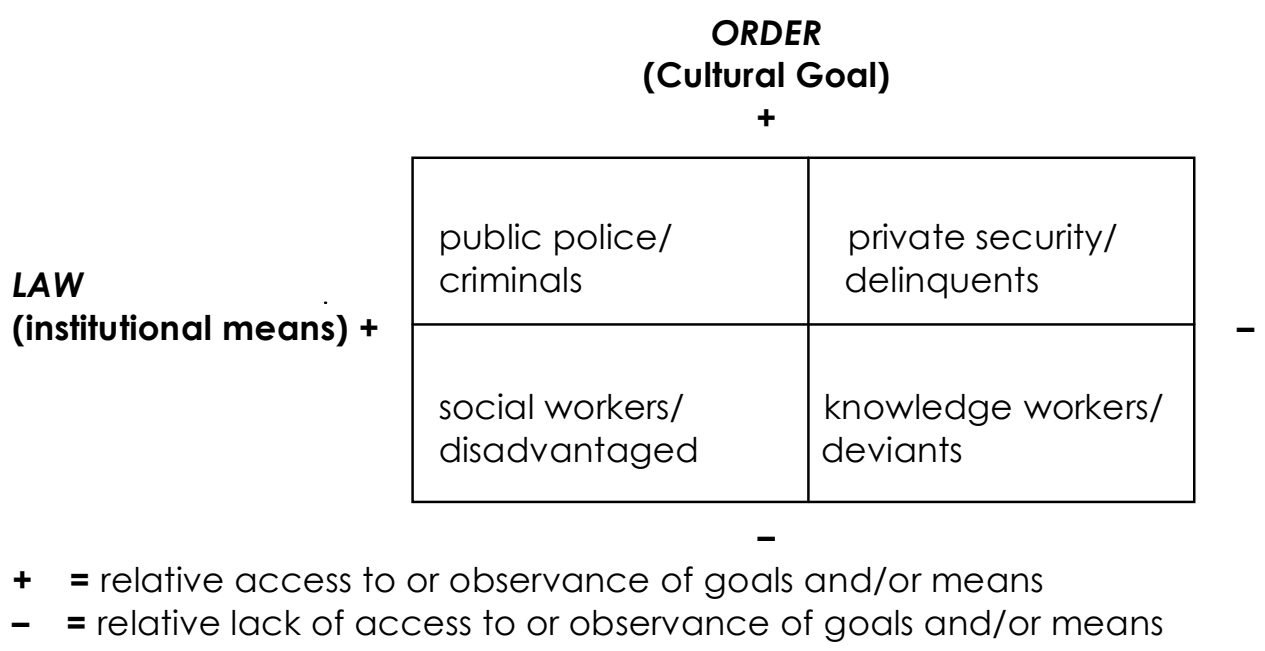

Figure 1: 'Broken Windows' as a Strategy of (Counter-)Surveillance on 'Skid Row'

In documenting the activities of mobile police patrols, neighbourhood watch programs and business improvement associations, other commentators have examined the 'broken windows' ideology specifically as a tactic of zero-tolerance law enforcement, as a cornerstone of so-called 'community policing,' or as an aspect of urban gentrification (Johnston and Shearing, 2003: 102; Huey, Ericson and Haggerty, 2005). By contrast, our objective here is to highlight the broader pattern by which observers themselves come under the gaze of observation within the contested space of interactions between institutional and individual agents on 'skid row.'

To be implemented effectively, 'broken windows' does not necessarily have to be formally sanctioned by legal statutes or officially recognized by the police. This method of maintaining order may also be informally enforced by security guards or merely socially approved by various social and knowledge workers, the latter term interpreted broadly to cover a range of public and private professionals (sometimes including academic researchers, a point we return to in the following section) concerned with collecting and sharing information on individuals and groups for various purposes. At the same time, understood as a multifaceted strategy of surveillance and countersurveillance, 'broken windows' may also be honoured or observed - if only in the breach

\footnotetext{
4 This schema is loosely inspired by Merton's (1957) classic typology of modes of individual adaptation, which he illustrates with reference to the broader American value-system that places a high premium on the goal of success through wealth. Here we narrow his frame of reference to focus specifically on the social structural strains and anomic cultural patterns on 'skid row,' which for the most part Merton characterizes in terms of the pattern of 'retreatism.' For a fuller discussion of Merton's general theory, including his displacement of the adaptation pattern of 'rebellion' (as well as social transformation and revolution) to a 'residual category,' (see Kemple, 2004: 7-10).
} 
- by numerous individuals who may not acknowledge or have direct access to the dominant codes of law and order, including those individuals who are its primary targets. For example, in the interests of maintaining order (at the 'upper half' of the diagram), the police are officially charged with keeping a close watch on suspected criminals, who attempt in turn to slip under their gaze, while private security officers stand guard against the covert and unruly actions of delinquents, who likewise try to elude them. In each instance, the identities of the various actors are mutually defined or undermined by their conflictual relationships and asymmetrical interactions with one another. By contrast, at the 'lower half' of this social space, other stakeholders may have more pressing concerns than upholding law and order, such as alleviating deprivations, reducing harm, or managing dependencies. For example, social workers are typically charged with looking out for the interests of disadvantaged (who are then expected to look after themselves), while knowledge workers of various kinds are expected to gather information on deviants (which may then be put to use in rehabilitating or normalizing them), regardless of whether these individuals are engaging in criminal or disorderly conduct. These designations then should not be understood as psychological states or character roles but rather as patterns of interaction and as locations within a social field. In particular, they refer to relations of exposure and (in)visibility, and of domination and (in)subordination, in which individuals may be engaged simultaneously or in succession at various times and depending on the circumstances. Thus, each of the stakeholders in the space depicted here can assume a fluid range of perspectives (or 'windows') on the field. Consequently, figure 1 does not represent fixed points on a map but offers a compass for navigating through the moving equilibrium of interests and shifting practices of surveillance and countersurveillance on 'skid row' (cf. Marx, 2004).

When the researcher enters this highly charged field of observation, she is necessarily and inextricably implicated in this grid of relationships. Fieldwork and observational research for the two ethnographic studies under consideration consisted primarily of touring the site (alone or with police or community outreach workers) or taking up a stationary position in public space to document physical and social landmarks and the ordinary lives of inhabitants and their interactions. In most instances the researcher simply sat or stood while quietly observing the people and the surroundings, sometimes taking notes or the occasional photograph. For the policing study if someone asked about her note-taking she explained the nature the research being conducted in general terms. On a few occasions, typically involving the observation of police activities, if the meaning of what she was witnessing was unclear, she would approach an officer, briefly describe her research project and ask for clarification. For the private security study she also undertook covert observation of security agents on patrol in public spaces. Thus, alongside the usual innocuous kinds of 'vernacular watching' that typically characterize urban life (often accompanied by the boredom and distraction experienced while waiting for 'something to happen') the disciplined observation of the researcher routinely entails modes of apparent voyeurism and 'suspicious looking' that often resemble the practices of surveillants and others engaged in the visual documentation of social space. For this reason, the researcher cannot avoid being positioned as a 'visual subject' in the field, that is, as an agent of sight (regardless of her physical ability to see) whose identity is constituted in large part by categories of (reciprocal) visuality, (mutual) observation, and/or (counter)-surveillance (cf. Mirzoeff, 2002). 
Many of these issues are graphically displayed in Illustration 1, an otherwise unremarkable photograph taken in the course of the private security study and which depicts a security guard questioning a local resident. Considered both in the context of the present paper and in its original setting, the photograph is as interesting for what it conceals as for what it reveals. In contrast to the activist or inflammatory intentions of photojournalism, the ethical conventions of social science research require researchers to alter the image to conceal the identities of the two individuals depicted. At the same time, the perspective assumed by the researcher/photographer also hides the technical and human conditions of the image's production, including the presence of the camera and of the photographer herself in this scene. Despite being 'off-stage' and 'out-of-frame,' these features of the image are indicative of the visual organization of the observational relationship with its alternation between overt activity and action incognito. Acknowledging these aspects of visual documentation also helps us to expose the paradox of photography in attempting to capture social reality by framing and immobilizing a moment - perceived as 'now/here' - within a succession of events (Becker, 1995). Thus, the particular physical and cultural boundaries of the area are 'screened' out of this image - such as the broader context of the 'broken windows' style of order-maintenance that had recently been intensified in this highly touristed and increasingly gentrified part of Vancouver's Downtown Eastside - and so too is the sequence of encounters of which this is only a frozen moment (a point we return to in the next section).

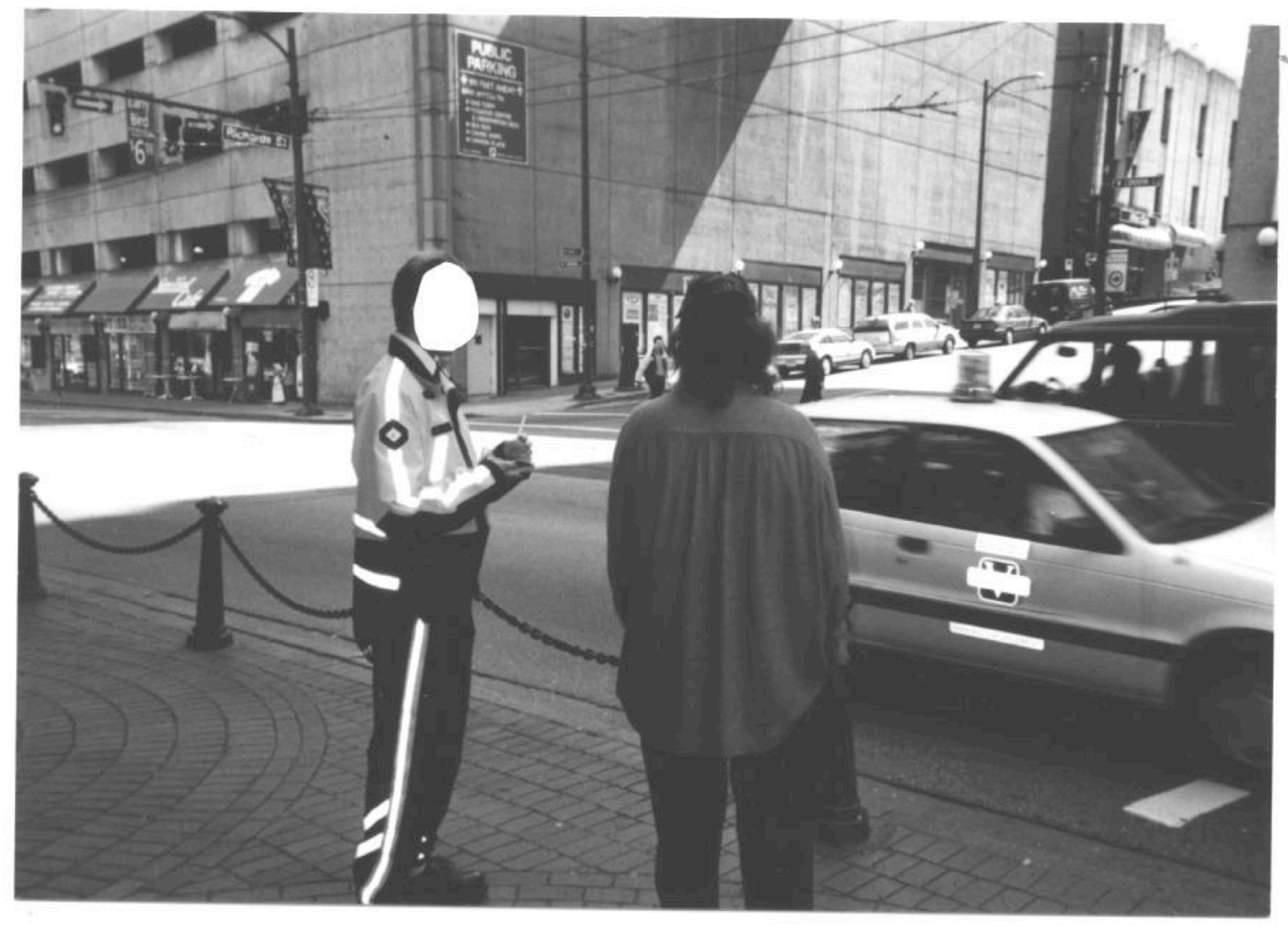

Figure 1: Security guard questioning a resident in Gastown, Vancouver (Photo: L. Huey)

Covert observation as a research strategy requires subjects either to be unaware of the fact 
that they are being observed, or to be unaware of the true purpose of that observation (Bowling, 1997). In the private security study, guards were covertly observed from either fixed vantage points (sidewalk benches, café seats, bus stops, etc.) or were discretely followed while on patrol. As guard patrols took place in public spaces in a tourist district, the researcher frequently dressed in shorts and carrying a camera as a way to blend in with the crowds of vacationing tourists (a deception that was not always successful, as we discuss below). In light of the ethical questions and methodological problems raised by several critics of the use of covert observation in the field (Lauder, 2003; Elms, 1994; Bulmer, 1982; Cassell, 1982), it is reasonable to ask why discrete surveillance of security guards on patrol is worth conducting as part of the fieldwork exercise.

One answer to this question is that in contested urban spaces, especially those characterized by high levels of crime, poverty, and insecurity and which are subject to unusually high levels of social control and regulation, it is not only addicts, prostitutes, pimps, drug dealers and 'deviant others' who may wish to keep certain activities hidden from public scrutiny. For example, the private security study was initiated at the request of a local community group who wished to examine the use of security agents as a mechanism for pushing the area's poor out of the neighborhood. Community residents advised that overt conspicuous forms of surveillance were being employed by guards as a means of harassing panhandlers and other disadvantaged residents (including homeless, unemployed, physically disabled and mentally ill people), and thus to induce them to abandon their use of public space. To the extent that these activities infringe upon the rights of some of the most vulnerable or oppressed urban inhabitants, the use of covert observation can be justified as necessary to expose activities which harm or oppress disadvantaged groups (Bok, 1978; Warwick, 1973). Such scrutiny reduces the likelihood that those being observed would alter their activities and gets around the tendency for people to deny such behavior in interviews (Turnock and Gibson, 2001). Thus, in instances where dense networks of control and multiple techniques of monitoring envelop virtually anyone who enters the field of observation, covert research 'may be the only way to develop accurate descriptions that are not affected by deliberate distortions, biased recollections, or outright denial' (Reynolds, 1982: 185). It may also help develop new perspectives on repressive relations and power structures.

A further consideration with respect to the use of covert methods concerns the claim that the inability to secure informed consent when using this strategy results in an invasion of subjects' privacy, thereby intensifying the anxiety and suspicion that citizens feel in a world that is perceived as increasingly subjected to information gathering and surveillance practices (Bulmer, 1980; 1982). All observational research for both studies occurred in public space, where the activities of those observed were potentially observable by anyone in this environment. At different times this might include several or several hundred individuals. As Homan (1980) suggests, individual and group expectations of privacy are considerably lessened when they operate within public forums, and thus where observers themselves may be the objects of observation. In the following section, we turn our attention to how this situation also poses significant methodological (as well as ethical) problems for the researcher when she is positioned as a target of surveillance or identified as an agent of (counter-)surveillance. In the concluding section we return to the question of whether these concerns point to what may be a more general structural dimension of social life beyond the contingent aspects of sociological research. If, as 
Niklas Luhmann (2002: 87) remarks, the inherent paradox of observation is that it 'has to operate unobserved in order to be able to cut up the world,' then the observation of observation is indispensable in understanding or rethinking such divisions.

\section{The Sociologist as Subject and Agent of (Counter-)Surveillance}

Knowing that targets of surveillance may respond in kind also can be a factor limiting or inhibiting the initial use of surveillance... Certainly there is greater equality in access to and use of surveillance technologies today than in much of recorded history. However, we are certainly far from equivalence here. The kind of technologies that are developed, apart from who has them, is also much affected by inequality of resources

(Marx, 2003: 384).

In the preceding discussion, we noted some of the ways in which field observations, can involve fairly routine activities of watching and asking, as well as the more systematic labour of tracking, recording, exposing, and documenting. These may require the use of techniques of concealment, disguise and anonymity not unlike those employed by other forms of surveillance. Of course, these techniques are normally part of an assemblage of analytical and observational methods which entail varying degrees of distance and contact, intimacy and objectivity, and may include surveys, interviews and psychological tests with their attendant audio and visual recording devices. Gary Marx's comment above regarding the increasing democratization of surveillance techniques (or at least their broader dissemination) points not only to the persistence of their unequal distribution and intensification but also to the potential for their neutralization or even subversion. The employment of counter-surveillance, as practiced in the communities we discuss here as well as in other social locations, thus can represent attempts to expose power asymmetries through the tactical use or disruption of surveillance techniques (Monahan, forthcoming). Rather than focus on the full array of these tactics of resistance and subversion, here we wish to examine the implications for field research when the observer is not only positioned as an active (and anonymous) surveillant, but also identified as an object of suspicion and targeted as a possible agent of (counter-) surveillance.

The reality of fieldwork in contested spaces is that on particular occasions an apparently disengaged observer frequently becomes part of the research setting through her immersion in the dynamics of exposure and concealment that characterize the field, and may thereby become an interactant with those who occupy these spaces. Her embeddedness is revealed as a consequence of the fact that all strangers in such sites are frequently subjected to varying levels of surveillance aimed at determining: 1) their identity, and thus 2) their potential threat to the observer and/or to others. In order to trace the effects of these interactions on the meaning and outcome of the research process, in what follows we examine three illustrations of a researcher's interactions in the field. In view of the preceding discussion it is perhaps significant that each of these encounters happen to break off through the medium of a window: at a café, through a camera lens, and on a bus.

For skid row denizens and other residents of the street, strangers can represent a possible 
source of danger to their businesses and to the conduct of other everyday activities. This potential threat is compounded in those instances when unknown individuals are spotted engaging in what appears to be more than casual watching. Typically police and social workers have sought to keep watch over skid row population in attempts to normalize 'deviant others' through coercive social work or spotting (potential) criminals for punishment by the justice system. Today, however, most residents are also aware that fellow neighbors, local workers, and business owners are being recruited into becoming willing surveillants and police informers, that is, into contributing to 'the broken windows' model as 'responsibilized' citizens (O’Malley, 1992; Garland, 1996). Careful scrutiny and identification of strangers by street residents themselves thus serves as a means of self-protection from the prying eyes of state authorities and the private institutions through which these authorities increasingly work.

An incident from the field - which might otherwise be regarded as too bizarre to be relevant to the analytical aims of a research project - serves to illustrate the embeddedness of the surveillance researcher within these contexts. During the spring of 2003 the Vancouver Police Department implemented a policing program, the City-wide Enforcement Teams (CET), which resulted in a public crackdown of the open-air drug market in its skid row district (the Downtown Eastside, or DTES). Throughout the summer of 2003, CET teams created an expanded and very visible police presence throughout the DTES: walking in pairs, on horseback, on motorcycles, bicycles, and in patrol cars, police used overt surveillance to break up pockets of the local drug market. An examination of CET both as an actual surveillance strategy and as a symbolic display of panoptic power formed a part of the larger public policing study. Over the course of several afternoons, fieldwork consisted of discrete but mostly overt observation of police observing (and being observed by) area residents. The following excerpts from field notes were taken while on break at a nearby coffee shop:

Writing up field notes in a coffee shop on Hastings [Street]. Female addict walks in and approaches. It is clear that she is 'dual-diagnosis' [addicted and mentally ill]. The conversation is strange. She has seen my notes and wants to know what I'm doing. I explain that I'm doing research on how the police treat people in her community. She becomes suspicious and angrier. She demands money. She tells me that she thinks I'm a 'narc,' and is going to tell her friends about me. She asks for money again, and when I say 'no,' she calls me a 'narc' in a loud voice (so that others in the restaurant can hear) and storms out the door. To find her friends, she says. She stares at me in the restaurant window for a minute, and then walks away. This is a serious threat. I quickly leave before she comes back

(field notes, August 15, 2003).

Although the peculiar features of this incident should not be underplayed, in view of the fairly common spectacle of uniformed patrol squads in this area (as depicted in Illustration 1 for instance) and sometimes plainclothes officers taking notes about suspicious people, the woman in the coffee shop had good reason to identify the researcher as a surveillant. While the technologies employed by the researcher were fairly unsophisticated (her gaze and pen and paper) the range of meanings behind their potential 
use was unmistakable to any observer in this highly charged though otherwise ordinary space. Despite repeated attempts by the research to explain the nature of her project, the woman persisted in misidentifying the role of the researcher: that is, as a police informant rather than as a sociological observer. At the same time, however, the researcher was able to instantly arrive at and sustain a view of the woman (whether correctly or not) as 'a female addict' and as 'dual diagnosis,' and thus to characterize her staring through the restaurant window as a potentially 'serious threat.' Once the identities of each participant in the encounter are assigned in this way, the subsequent interaction and its outcome (the woman yelling, the researcher escaping) seem to be virtually assured. If we return to the surveillance schema represented in Figure 1 (particularly the lower right quadrant), we can see how both the identity and the security of observer and observed may be challenged or established on the basis of their (presumed or actual) mutual knowledge and ignorance of their respective social location within the space.

The sociological observer in the field ostensibly seeks to acquire knowledge of social processes. Her goal is not to affirm or support the cultural goal (order) of the setting under examination or to affirm or support the institutional means of meeting this goal (law). Rather it is to sustain an interest in disinterestedness, that is, to engage as much in participant observation as in participant objectification. Her task is to expose the ways in which human subjects are transformed into objects of power and knowledge, including how this transformation takes place through the process of research itself (Bourdieu, 2004). Whatever her moral sympathies or political commitments, the researcher does not need to have access to or endorse the goals and means (the subcultural values or official institutions) that define the field of study. In employing surveillance techniques as a strategy for gathering information for research purposes, she may nevertheless be seen to operate as a 'deviant' counter-surveillant in a relation of opposition to the established codes of law and order. In part, this perception arises from the circumstance that, as a 'knowledge worker,' her primary location in the field is not as an informant working on behalf of authorities charged with enforcing law and maintaining order in this setting. Rather, as an academic researcher (in fact, one of many who have turned their gaze on 'skid row' since the early days of urban sociology) she is also an actor within the university field, particularly insofar as her notes and analyses (for example) are employed for the accumulation of educational capital or in gaining symbolic recognition through publication.

The potential misidentification of the researcher as a formal agent of surveillance - as a 'narc' - encompasses a range of potentially serious methodological as well as ethical implications for the conduct and outcome of research on skid row. As in other communities, police on 'the skids' function on behalf of the goal of order. Those seen as being 'on the other side,' as one addict interviewed referred to her 'deviant' status (or in other words, as occupying the 'lower end' of the slash in each of the quadrants of Figure 1), are the usual targets of police surveillance, often leading to the loss of their livelihood, to their eventual arrest, or even to 'starlighting' (the practice of dumping a suspected criminal or disorderly person in another part of the city, or sometimes outside city limits). As a consequence, individuals identified as 'narcs' may find themselves subjected to 'preventative' or retributive treatment from other individuals in this community (Rosenfeld, Jacobs and Wright, 2003). In the course of conducting fieldwork in San Francisco's Tenderloin district, for example, an undercover police officer working a low- 
level drug buying operation was stabbed by a drug dealer who had identified him as a police officer. As such incidents were not uncommon in the areas where interviews and field observations are being conducted (within two or three blocks, in the San Francisco case), the researcher had to take seriously the types of accusatory threats like those posed by the woman in the coffee shop. Nevertheless, insofar as knowledge-gathering activities in 'skid row' neighborhoods (including those contributing to university based projects) are frequently viewed with confusion and distrust, it is unlikely that even a correct perception of the researcher's intentions (in this instance, as suggested perhaps in the woman's initial demand for money) would be enough to erase all suspicions.

In light of the possibility that the researcher may be mistakenly identified as an informer by skid row residents, it is somewhat ironic that, under the banner of 'broken windows,' she may also find herself treated as a potential threat to middle class community order. As noted above, 'broken windows' is deployed not just as a model for training police and security guards to scrutinize spaces for criminogenic cues, but also as a framework for maintaining the appearance of civic order as it is normatively defined by values and meanings found predominately in white middle-class neighborhoods (Huey, Ericson and Haggerty, 2005; Harcourt, 2001). In the process, a variety of civic agents are 'responsibilized' to adopt and promote this narrowly defined goal in informal ways (such as casual or conspicuous observation of one's neighbors) and through formal channels (for example, association and support for institutionalized surveillance programs, including policing and private security systems). Thus, residents seen as 'disorderly' or as threats to newly imposed community norms are likely to find themselves not only under the gaze of security guards and police officers, but also under the watchful eyes of neighbors, area workers and local businesses.

During fieldwork for the private security study, evidence of how surveillance practices can become an aspect of 'broken windows'-inspired vigilance was acquired firsthand when the researcher found herself targeted as a potential threat to community security. In this second example, she was conducting routine fieldwork by visually documenting aspects of the built environment with a camera, as described in the following field notes:

Have located the Community Police Office. It is closed. I attempt to take a picture of it, but have difficulty due to the glare of the glass. As I maneuver around trying to take a picture, I observe a man watching me with interest. I give up on the photo and move to the corner of Abbott and Water streets. The man follows me and continues to observe me. I stand there for a couple of minutes to see what he will do. He stands there and watches me. I decide to turn west and move on. While watching a guided tour group, I notice the same man is walking towards me from the west side of the street (he must have taken a short cut). He sees me and stops. I make deliberate eye contact. I continue walking, he continues following me. I dart into a store and look at items for a moment, check the store window and see that he is looking in. I exit and continue walking. As he is still following me, I decide to walk to an area where I can sit down and observe the length of Water Street. I sit down and take out my camera. He stops twenty or so feet away from me, directly in my line of sight. I line up a camera shot and as he attempts to 
move out of camera range I take his picture [Figure 2]. He then moves away ... suspect that he is security personnel ... the technique he used is similar to that of the security guards: overtly follow a target, but don't make contact (intimidation)

(field notes of June 17, 2000).

The suspicion that this individual had received security training was supported in the course of a subsequent interview with a police officer who promotes 'broken windows' policing through his training of community patrols designed to protect area businesses. In the officer's view it was likely this individual was a local merchant seeking to prevent a potential burglary. This speculation was subsequently confirmed when the researcher recognized the mystery surveillant behind the counter of a local shop. As the officer explains,

One of the guys that I supervised as a civilian in the Crime Watch, he helped those guys out and he created the Gastown patrol. I know that the training that he got, he did share with [area merchants]. And a lot of it was training in lower level observation. So I can see the guy circling the block. He's probably thinking about how clever he is (laughs).

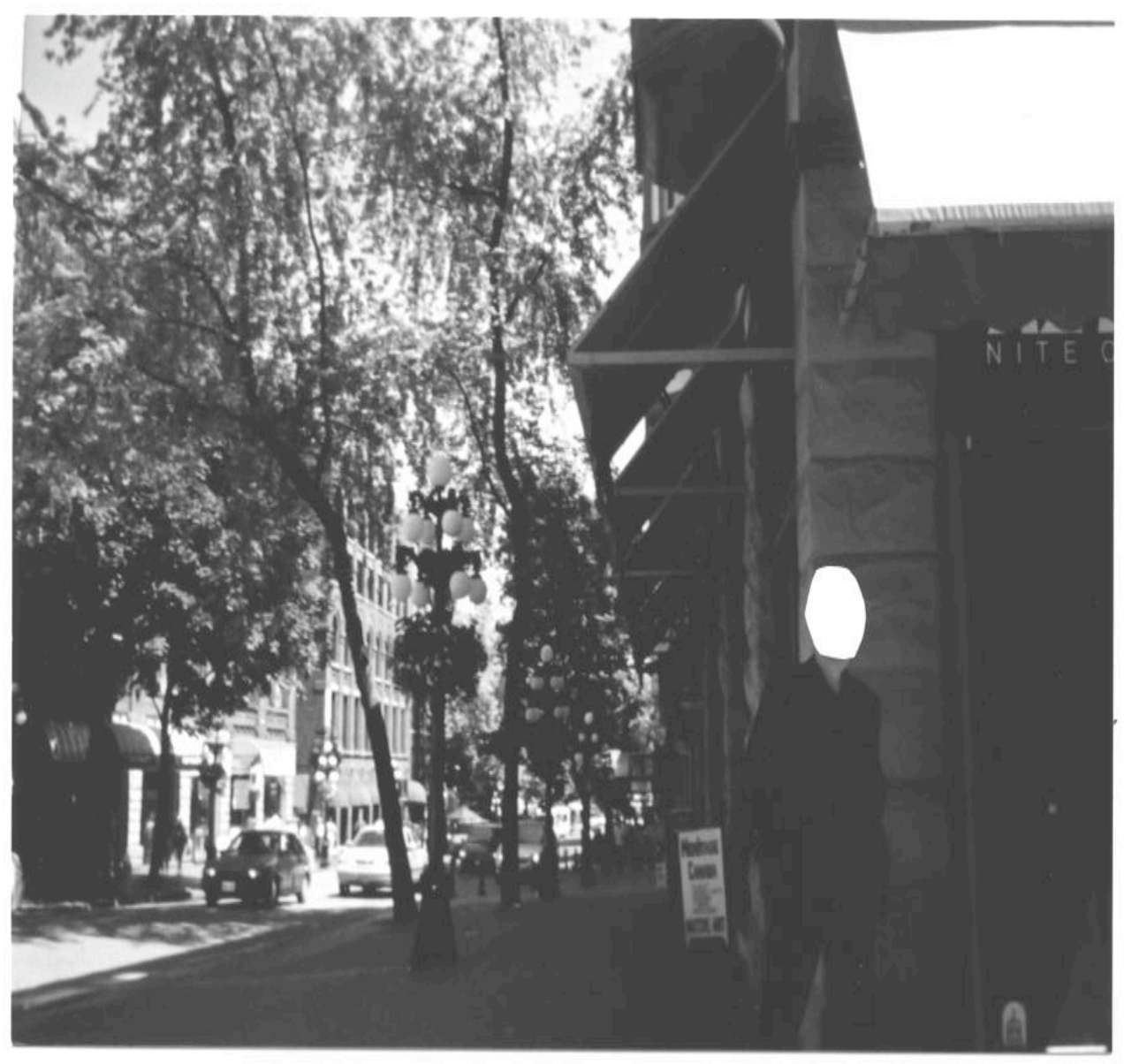

Illustration 2: Mystery surveillant, Gastown (photo: L. Huey). 
This encounter allows us to appreciate how actions that otherwise appear innocuous (or ridiculous) may be viewed through the lens of 'the broken windows theory' as (potential) threats to the dominant order. The merchant in this example sees himself as working on behalf of community security. Moreover, he is using what he believes to be socially sanctioned means in support of this goal - after all, his training has come courtesy of the local police department (through the auspices of the local community watch group) which clearly has a vested interest in increasing the number of 'eyes and ears' on the street (Harcourt, 2001). That the target of his observation happened to be what the police would view as a 'legitimate' space user (in this case, a law abiding citizen engaged in authorized academic research) rather than the illegitimate target that the man suspected her to be, serves as a source of amusement for the officer (an advocate of this policing system) rather than as a cautionary tale illustrating the perils of unrestrained surveillance. At the same time, the incident inadvertently illustrates how the academic researcher herself, especially when equipped with a camera and defying intimidation, may be suspiciously viewed as a potentially subversive agent of counter-surveillance.

A third example of the treatment of the skid row researcher within this context further illustrates the possible implications of her identification as a counter-surveillant, in this case with respect to those functioning as formal agents of surveillance. As noted above, during the private security study, the surveillance activities of security guards were routinely documented in notes and occasionally in photographs. While taking the photograph discussed in the previous section depicting a security guard questioning a local resident (see Figure 1), fellow officers were alerted to the presence of the suspicious activities of the photographer/researcher who was accidentally caught in the act of observing and recording the officer's observations. The following excerpt is from field notes taken immediately after the researcher was spotted by the guard:

I see that the guard is there. He is talking on a walky-talky. He seems to be observing me, but is not approaching ... I have definitely been spotted. I decide to cross the street and I see the male guard is now with the female guard. I cross the street to observe them. They are standing almost directly across the street from me and are both directly watching me and taking notes. I feel that they are trying to intimidate me. I continue to watch and take notes. A bus comes and I head towards it. The female guard leaves. The male guard stays on spot, taking notes. I board the bus. He watches me through the bus window. I wave to him. No response.

(field notes of May 30, 2000).

While studying the use of overt surveillance techniques by guards directed at local residents, the researcher became identified by the guards as a counter-surveillant, and therefore as an object of concern. At one level the identification was correct: in this situation, through the use of what were (up to this point) covert observation techniques, the researcher was evidently operating as a counter-surveillant. However, as in the preceding examples, her purpose was misrecognized as a potential threat to order or to their ability to carry out their mandate to uphold a commercially defined normative order in this space. As with the two preceding examples, the researcher's activities were misunderstood as a result of the suspicions that attach to the use of observation techniques 
by differently situated actors within this contested space. The broken windows model of upholding community order, with its emphasis on proliferating the conspicuous surveillance of activities within an area, exacerbates the underlying tensions within this community through the requirement that all activities and individuals that do not conform to dominant normative expectations be treated as objects of suspicion. Ironically, the researcher might also have appeared to each party as fulfilling a function that either would view as legitimate and potentially useful to their interests, for example, as an informant with evidence of criminal activity or an activist documenting police abuse. In any case, even when an academic observer is removed from these conflicts she may still be caught in the intersection of gazes, and thus embedded in the knowledge base and power-network of surveillance and counter-surveillance, that constitutes this space.

\section{Conclusion: Sociological Reflexivity and the Politics of Research on 'Skid Row'}

[In control societies], individuals become 'dividuals,' and masses become samples, data, markets, or 'banks' ... Disciplinary man produced energy in discrete amounts, while control man undulates, moving among a continuous range of different orbits

(Deleuze 1995: 180).

Our discussion of the serious game of hide and seek that is sometimes played between a variety of stakeholders on 'skid row' needs to be placed within the context of both the broader theoretical questions that are raised by sociological observation, as well as some of the specific ethical issues posed by the unique features of this space. In one of his last comments on the 'reflexive problem' in sociology, Pierre Bourdieu (2004: 86, 89) provides a useful introduction to these questions with regard to what he refers to as the constitution of a sociological 'vision of reality' and the composition of a scientific 'point of view':

To bring to light what is 'the hidden' par excellence, what escapes the gaze of science because it is hidden in the very gaze of the scientist, the transcendental unconscious, one has to historicize the subject of historicization, to objectivate the subject of the objectivation ... To be able to apply to their own practice the objectivation techniques that they apply to the other sciences, sociologists have to convert reflexivity into a disposition constitutive of their scientific habitus, a reflexivity reflex.

Bourdieu's suggestion that the action and location of the sociological enterprise can be illuminated by the historicizing and objectivizing methods of science entails acknowledging the research situation itself as a mode of social interaction in its own right. That is, the sociological perspective, what he refers to as the 'principles of vision and division' of its 'scientific habitus,' consists of a distinctive disposition that is cultivated and constrained within overlapping fields of social interaction, competence, and power relations. As Luhmann (2002) might point out, the examples we have cited above suggest that the irreducible blind spot of sociology may well be the systematic organization of its own observational gaze, or at least the visual organization of the social and cultural fields 
it both inhabits and examines. For this reason, rather than attempting to reconcile the polarized attitudes of objectivism versus subjectivism, or even of passionate engagement versus cool detachment, our aim here has been to exercise this 'reflexivity reflex' by exposing how these tensions are often bound up with powerful patterns of revelation and concealment that are sometimes beyond our ability to fully account for or control.

As the above illustrations suggest, the limits of scientific objectification are also the limits of disciplined observation, at least as long as the methodological procedures such observation entails are carried out according to a sociological project within contemporary settings that are already thoroughly surveyed and 'sociologised.' Not only are social groups often made 'knowable' under the gaze of social science through the application of discrete classification systems, but such information can also be accumulated, checked, stored, retrieved and compared for use in assessing the risks and opportunities these groups may pose (Lyon, 2002: 3). Institutional and informal techniques of sociological observation and everyday surveillance increasingly overlap with and reinforce one another when human subjects are documented, interviewed, photographed, and profiled, often with the aim of controlling or intervening in the daily conduct of their affairs in a 'neutral' way or 'at a distance.' H. T. Wilson (2004: 296) has commented on this feature of social science research as constitutive of the institutions that support it:

The social, behavioural, and administrative/managerial sciences have become part of the institutional structure of the advanced societies... Nowadays these disciplines serve as a model for social practice rather than simply a way of studying the nature of commonsense activities that take place independently of their interests and values. In effect, they have become a veritable force of production in their own right, all the more successful in this endeavor where the fact of their influence has been muted by internalized acceptance of their commitment to observe, record, even intervene sine ira et studio.

The social sciences are increasingly in a position to offer legitimacy and rationality to procedures of gathering data, examining evidence, reporting information, and formulating classifications that are integral to the routine operation of non-academic institutions, both public and private. Such methods may be mobilized to contribute to governmental objectives of coercion and normalization, for example, or they may be redeployed collaboratively in an effort to account for and transform conventional ways of accumulating social, educational and professional capital (Wilson, 2004: 313-327; Culhane, 2003/04). In any case, neither scenario can avoid the fact that the research enterprise itself is implicated in relations of mutual observation or even in techniques of (counter-)surveillance that have ethical and not simply theoretical implications.

The insuperable challenge for researchers immersed in a precariously configured setting like 'skid row' is that many of the people and places in question are themselves subject to imperatives of mobility and transience that are enforced in large part by the police and other agents of order: "The police are primarily concerned with making manifest what is there, or rather, what is not there: 'Move along, there's nothing to see" (Rancière, 1998: 242). At the risk of being positioned as an agent of social control or targeted as a subject of surveillance, the researcher assumes a position within this circulating flux of observers observing observers being observed. There is a sense in which modern social science and modern surveillance were each from their earliest days a means of 'keeping tabs on the 
mobile,' and yet today both are components in a much larger assemblage and part of the flow (Lyon, 2002: 3; Haggerty and Ericson, 2000). Among the ironies of the supposed 'democratization of surveillance' is that many of the most marginalized and mobile subjects of observation are already hypervisible and hypervigilent by virtue of their lack of access to private and protected places, and yet at the same time they remain largely unseen and unaccounted for, forgotten and unheard from (Archand, 1979). To understand the conditions that unequally affect the most vulnerable, exposed and invisible urban dwellers, and to reconfigure what there is to see and do in the spaces we share, researchers can move beyond simply observing, enumerating and documenting only by acknowledging the dialectic of visibility and invisibility which envelops the lives of each and everyone of us.

\section{References}

Archand, P. (1979) Vagrancy, Alcoholism, and Social Control. London: Macmillan.

Becker, H. S. (1995) Visual Sociology, Documentary Photography and Photojournalism: It's Almost All a Matter of Context. Visual Sociology 10: 5-14.

Bok, S. (1978) Lying: Moral Choice in Public and Private Life. New York: Pantheon.

Bourdieu, P. (2004) Why the Social Sciences Must Take Themselves as their Object. In Science of Science and Reflexivity. Chicago: University of Chicago Press, 85-114.

Bowling, A. (1997) Research Methods in Health. Buckingham, U.K.: Open University Press.

Bulmer, M. 1(980) Comment on 'The Ethics of Covert Methods.' The British Journal of Sociology 31 (1): $59-65$.

Bulmer, M. (1982) The Merits and Demerits of Covert Participant Observation." In Social Research Ethics: An Examination of the Merits of Covert Participant Observation, edited by M. Bulmer. New York: Holmes \& Meier, 217-251.

Cassell, J. (1982) "Harm, Benefits, Wrongs, and Rights in Fieldwork. In The Ethics of Social Research: Fieldwork, Regulation, and Publication, edited by J. Sieber. New York: Springer-Verlag, 7-31.

Culhane, D. (2003/2004) Documenting Time and Restricted Space: University and Community Women in Downtown Eastside Vancouver. BC Studies 140: 91-106.

Deleuze, G. 1(995) Postscript on Control Societies. In Negotiations 1972-1990, M. Joughin (trans.) . New York: Columbia University Press, 177-182.

Ellickson, R. (1996) Controlling Chronic Misconduct in City Spaces: Of Panhandlers, Skid Rows, and Public-Space Zoning. The Yale Law Journal 105 (5): 1165-1248.

Elms, A. (1994) Keeping Deception Honest: Justifying Conditions for Social Scientific Research Stratagems. In Ethical Issues in Scientific Research: An Anthology, edited by E. Erwin, S. Gendin, and L. Kleiman. New York: Garland, 121-140.

Garland, D. (1996) The Limits of the Sovereign State: Strategies of Crime Control in Contemporary Society. The British Journal of Criminology 26: 445-467.

Haggerty, K.D. and R.V. Ericson (2000) The Surveillant Assemblage. British Journal of Sociology 51 (4): 605-622. 
Harcourt, B. (2001) Illusion of Order: The False Promise of Broken Windows Policing. Cambridge, MA.: Harvard University Press.

Hasson, S. and D. Ley (1994) The Downtown Eastside: 'One Hundred Years of Struggle.' In Neighborhood Organizations and the Welfare State. Toronto: University of Toronto Press, 172-204.

Homan, R. (1980) The Ethics of Covert Methods. The British Journal of Sociology 31(1): 46-59.

Huey, L. (2005) Negotiating Demands: The Politics of Skid Row Policing in Vancouver, San Francisco and Edinburgh (unpublished manuscript).

Huey, L. and T.M. Kemple (2005) 'Let the Streets Take Care of Themselves': Making Historical, Sociological and Common Sense of 'Skid Row' (unpublished manuscript).

Huey, L., R. Ericson and K. Haggerty (2005) Policing Fantasy City. In Re-imagining Policing in Canada, edited by D. Cooley. Toronto: University of Toronto Press, 140-208.

Johnston, L. and C. Shearing (2003) Governing Security: Explorations in Policing and Justice. New York: Routledge.

Kelling, G. and C. Coles (1996) Fixing Broken Windows: Restoring Order and Reducing Crime in Our Communities. New York: Martin Kessler Books.

Kemple, T. M. (2004) Editor's Note to Part I: The Limits of 'Rationality'. In The Vocation of Reason: Studies in Critical Theory and Social Science in the Age of Max Weber, edited by T.M. Kemple. Leiden, The Netherlands: Brill, 3-14.

Lauder, M. (2003) Covert Participant Observation of a Deviant Community: Justifying the Use of Deception. Journal of Contemporary Religion 18 (2): 185-196.

Luhmann, N. (2002) Paradox of Observing Systems. In Theories of Distinction: Redescribing the Descriptions of Modernity, edited by William Rasch, translated by J. O'Neil. Stanford, CA: Stanford University Press, 79-93.

Lyon, D. (2002) Surveillance Studies: Understanding Visibility, Mobility, and the Phenetic Fix. Surveillance \& Society 1 (1): 1-7. http://www.surveillance-and-society.org/articles1/editorial.pdf

Marx, G. T. (2003) A Tack in the Shoe: Neutralizing and Resisting the New Surveillance. Journal of Social Issues 59 (2): 369-390.

Marx, G. T. (2004) Surveillance and Society, in Encyclopedia of Social Theory, $2^{\text {nd }}$ ed., edited by George Ritzer. Thousand Oaks, CA: Sage, 275-280.

Merton, R.K. (1949) Social Structure and Anomie. In Social Theory and Social Structure. Glencoe, IL: The Free Press, 131-160.

Mirzoeff, N. (2002) The Subject of Visual Culture. In The Visual Culture Reader, edited by N. Mirzoeff . London: Routledge, 3-21.

Monahan, T. (forthcoming) Counter-Surveillance as Political Intervention? Social Semiotics.

O’Malley, P. (1992) Risk, Power and Crime Prevention. Economy and Society 21 (3): 252-275.

Rancière, J. (1998) Dix thèses sur la politique. In Aux bords du politique. Paris: Gallimard, 223-254.

Reynolds, P. (1982) Moral Judgments: Strategies for Analysis with Application to Covert Participant Observation, in Social Research Ethics: An Examination of the Merits of Covert Participant 
Observation, edited by. M. Bulmer. New York: Holmes \& Meier, 185-213.

Rose, N. (1999) Powers of Freedom: Reframing Political Thought. Cambridge, UK: Cambridge University Press.

Rosenfeld, R., B. Jacobs and R. Wright (2003) Snitching and the Code of the Street. British Journal of Criminology 43 (2): 291-309.

Staples, W. (2000) Everyday Surveillance: Vigilance and Visibility in Postmodern Life. Lanham, Md. : Rowman \& Littlefield.

Turnock, C. and V. Gibson (2001) Validity in Action Research: A Discussion On Theoretical and Practical Issues Encountered whilst using Observation to Collect Data. Journal of Advanced Nursing 36 (4): 401-411.

Warwick, D. (1973) Survey Research and Participant Observation: A Benefit-Cost Analysis. In Comparative Research Methods, edited by D. Warwick and S. Osherson. Englewood Cliffs: Prentice-Hall, 189-203.

Wilson, H. T. (2004) Essential Process of Modernity: A Critical Analysis of Social Science Research Practices and an Alternative. In The Vocation of Reason: Studies in Critical Theory and Social Science in the Age of Max Weber, edited by T. M. Kemple. Leiden, The Netherlands: Brill, 295329.

Wilson, J. and G. Kelling (1982) Broken Windows: The Police and Neighborhood Safety. Atlantic Monthly (March): 29-38. 